\title{
33. URANIUM AND THORIUM ISOTOPES: DEEP SEA DRILLING PROJECT, LEG $23^{1}$
}

\author{
Teh-Lung Ku, Department of Geological Sciences, University of Southern California, \\ Los Angeles, California
}

\section{INTRODUCTION}

Sediment samples taken from Sites 228 and 229 were received for analyses of the longer-lived uranium and thorium series nuclides; namely, $\mathrm{U}^{238}, \mathrm{U}^{234}, \mathrm{Th}^{230}$, and $\mathrm{Th}^{232}$. These sediments were of the silty calcareous ooze type with varying calcium carbonate contents and with colors ranging from dusty yellow to greenish gray. Site 229 samples were more grayish and, when received at our laboratory, were in the form of pressed cakes with interstitial water already extracted for chemical studies.

Measurements of the above-mentioned isotopes were carried out for the following purposes:

1) To attempt to delineate sedimentation rates from the amount of the excess $\mathrm{Th}^{230}$ (i.e., uranium-unsupported) present in these sediments;

2) To detect from the ratios $\mathrm{Th}^{230} / \mathrm{U}^{234}$ and $\mathrm{U}^{234} / \mathrm{U}^{238}$ if any post-depositional migration of uranium and thorium isotopes had occurred, as samples from great depths, because of their ages, would be expected to show radioactive equilibrium relationship among these nuclides;

3) To assess the uranium and thorium concentrations in sediments of this relatively land-locked oceanic basin and compare them with those of open-ocean, pelagic deposits.

\section{PROCEDURES}

Samples were digested with $\mathrm{HCl}$, then fumed with a mixture of $\mathrm{HF}-\mathrm{HClO}_{4}$ to effect total dissolution. Known amounts of $\mathrm{U}^{232}$ and $\mathrm{Th}^{228}$ were added to the solutions to serve as yield tracers. Uranium and thorium isotopes were then separated and purified through ion-exchange and solvent extraction steps and mounted as thin sources for alpha-spectral analyses. Detailed procedures followed essentially those described by $\mathrm{Ku}$ (1965). Calcium carbonate contents were assayed by gasometric measurement of $\mathrm{CO}_{2}$ released upon acidification using a LECO (Laboratory Equipment Corporation) instrument (Kolpack and Bell, 1968).

\section{RESULTS AND DISCUSSION}

Table 1 lists the analytical results. The errors indicated are standard deviations (one sigma) based on counting statistics. Precision of the $\mathrm{CaCO}_{3}$ measurements is about $\pm 1 \%$.

The $\mathrm{Th} / \mathrm{U}$ ratio generally reflects the oxidation potential of a depositional environment (Goldberg, 1965). The larger the ratio, the more oxidizing sedimentary regime it denotes. The explanation involves the difference in solubilities of

\footnotetext{
${ }^{1}$ Contribution No. 320, Department of Geological Sciences, University of Southern California.
}

uranium in its two oxidation states: $\mathrm{U}^{+4}$ and $\mathrm{U}^{+6}$. Under oxidizing conditions, uranium is in +6 state and can be strongly held in solution through the uranyl complexes such as $\mathrm{UO}_{2}\left(\mathrm{CO}_{3}\right)_{3}{ }^{-4}$. Thus $\mathrm{Th} / \mathrm{U}$ increased from shales $(\sim 4)$ to deep-sea clays $(\sim 5)$ and manganese nodules (as high as 20). The consistently low $\mathrm{Th} / \mathrm{U}$ ratio of the Red Sea sediments (Table 1) attests to the fact that they represent a redox potential system much lower than open ocean deposits. Data on Site 228 sediments are very similar to those of a nearby piston core (154P) reported earlier $(\mathrm{Ku}$, 1969). Their uranium contents are comparable to those of average shales and pelagic clays $(\sim 2-3 \mathrm{ppm})$. Their thorium content, however, is distinctively lower $(5-7 \mathrm{ppm}$ on a carbonate-free basis as opposed to $10-12 \mathrm{ppm}$ for shales and deep-sea clays). Sediments at Site 229 are characterized by abnormally high uranium. This further lowers the Th/U ratios and denotes highly reducing conditions. The question arises: Did such enrichment of uranium occur postdepositionally or syngenetically?

Table 1 shows that in the two deep sections of Hole $229 \mathrm{~A}, \mathrm{Th}^{230}$ is greatly depleted relative to $\mathrm{U}^{234}$. With a sedimentation rate on the order of $580 \mathrm{~m} / \mathrm{m} . \mathrm{y}$. (cf. Report on Sedimentation Rate, Site 229), the age of 229A-5-6 is about 130,000 years. If all of its uranium were syngenetic, i.e., uranium was incorporated into the sediments when the latter were accumulated, then the sediments would initially be totally devoid of $\mathrm{Th}^{230}$ in order to acquire the present $\mathrm{Th}^{230 / \mathrm{U} 234}$ ratio of $0.66 \pm 0.07$. In other words, the $\mathrm{Th}^{230} / \mathrm{U}^{234}$ ratio of the sediments would be zero at the time of deposition. Although possible, the fact that a significant amount of $\mathrm{Th}^{232}$ is found in the deposits makes the zero $\mathrm{Th}^{230}$ hypothesis highly improbable. In $229 \mathrm{~A}-5-6$, the activity ratio of $\mathrm{Th}^{232} / \mathrm{U}^{234}$ is equal to 0.15 . The introduction of $\mathrm{Th}^{232}$ into the sediments must have also been accompanied by some of its isotope, $\mathrm{Th}^{230}$. Since the average crustal $\mathrm{Th}^{232} / \mathrm{Th}^{230}$ (activity ratio) as determined by the relative abundance of uranium to thorium is about one, it can be argued that the sediments initially had a finite $\mathrm{Th}^{230} / \mathrm{U}^{234}$ value on the order of 0.15 instead of zero. This means that the age of 229A-5-6 should be about 80,000 years rather than 130,000 years. In the case of 229A-2-1, its having initially contained $\mathrm{Th}^{230}$ is almost certain in view of its shallow depth and young age $(\sim 50,000$ $\mathrm{yr}$ if a rate of $580 \mathrm{~m} / \mathrm{m} . \mathrm{y}$. is assumed). Therefore, unless the above-mentioned sedimentation rate estimate is unreasonably low, a more consistent interpretation of the $\mathrm{Th}^{230}$ / U234 data calls for a post-depositional migration of uranium. As decay of organic matter in the sediments was taking place, uranium could have been transported through the pore solution medium and continuously precipitated in the more reduced layers. Such a process could have also operated at Site 228 , though to a far less extent. This 
TABLE 1

Uranium and Thorium Isotopes in Leg 23 Sediments

\begin{tabular}{|c|c|c|c|c|c|c|c|c|}
\hline Sample ${ }^{a}$ & $\begin{array}{l}\text { Depth } \\
(\mathrm{cm})\end{array}$ & $\begin{array}{c}\mathrm{CaCO}_{3} \\
(\%)\end{array}$ & $\underset{(\mathrm{ppm})}{\mathrm{U}^{\mathrm{c}}}$ & $\begin{array}{l}\mathrm{Th}^{\mathrm{c}} \\
\text { (ppm) }\end{array}$ & $\frac{\mathrm{Th}}{\mathrm{U}}_{\mathrm{wt}}$ & $\frac{\mathrm{U}^{234^{\mathrm{d}}}}{\mathrm{U}^{238}}$ & $\frac{\mathrm{Th}^{230^{\mathrm{d}}}}{\mathrm{U}^{234}}$ & $\begin{array}{l}\mathrm{Th}_{e x}^{230^{\mathrm{e}}} \\
\text { (dpm/g) }\end{array}$ \\
\hline $228-1-1$ & $0-10$ & 22.2 & $\begin{array}{c}1.38 \pm 0.06 \\
(1.77 \pm 0.08)\end{array}$ & $\begin{array}{c}3.72 \pm 0.16 \\
(4.78 \pm 0.21)\end{array}$ & 2.70 & $0.93 \pm 0.05$ & $1.25 \pm 0.09$ & $0.24 \pm 0.07$ \\
\hline $228-1-2$ & $105-107$ & 9.0 & $\begin{array}{c}3.21 \pm 0.14 \\
(3.53 \pm 0.15)\end{array}$ & $\begin{array}{c}5.44 \pm 0.23 \\
(5.97 \pm 0.25)\end{array}$ & 1.70 & $1.12 \pm 0.06$ & $0.78 \pm 0.04$ & $-0.59 \pm 0.14$ \\
\hline $228-1-3$ & $286-288$ & 14.8 & $\begin{array}{c}1.66 \pm 0.07 \\
(1.95 \pm 0.11)\end{array}$ & $\begin{array}{c}4.27 \pm 0.27 \\
(5.01 \pm 0.32)\end{array}$ & 2.57 & $0.95 \pm 0.05$ & $0.91 \pm 0.07$ & $-0.10 \pm 0.09$ \\
\hline $228-1-4$ & 484 & 54.5 & $\begin{array}{c}1.53 \pm 0.07 \\
(3.36 \pm 0.15)\end{array}$ & $\begin{array}{c}2.38 \pm 0.21 \\
(5.23 \pm 0.46)\end{array}$ & 1.56 & $1.04 \pm 0.06$ & $0.82 \pm 0.05$ & $-0.21 \pm 0.06$ \\
\hline $228-3-1$ & 2440 & 18.3 & $\begin{array}{c}2.23 \pm 0.13 \\
(2.73 \pm 0.16)\end{array}$ & $\begin{array}{c}4.89 \pm 0.38 \\
(5.98 \pm 0.47)\end{array}$ & 2.19 & $0.98 \pm 0.07$ & $1.08 \pm 0.09$ & $0.13 \pm 0.07$ \\
\hline $228-5-1$ & 3300 & 32.1 & $\begin{array}{c}1.90 \pm 0.05 \\
(2.80 \pm 0.07)\end{array}$ & $\begin{array}{c}3.89 \pm 0.20 \\
(5.73 \pm 0.29)\end{array}$ & 2.05 & $1.03 \pm 0.03$ & $1.10 \pm 0.05$ & $0.14 \pm 0.05$ \\
\hline $229-1-\mathrm{CC}$ & $200-210$ & 69.4 & $\begin{array}{r}18.6 \pm 0.37 \\
(60.8 \pm 1.2)\end{array}$ & $\begin{array}{c}2.49 \pm 0.13 \\
(8.14 \pm 0.42)\end{array}$ & 0.13 & $1.02 \pm 0.01$ & $0.91 \pm 0.03$ & $-1.20 \pm 0.42$ \\
\hline $229 \mathrm{~A}-2-1$ & $2900-2910$ & 64.9 & $\begin{array}{c}8.13 \pm 0.18 \\
(23.2 \pm 0.51)\end{array}$ & $\begin{array}{c}2.75 \pm 0.08 \\
(7.82 \pm 0.23)\end{array}$ & 0.33 & $1.11 \pm 0.02$ & $0.58 \pm 0.02$ & $-2.79 \pm 0.17$ \\
\hline $229 A-5-6$ & $7250-7260$ & 45.8 & $\begin{array}{c}8.57 \pm 0.45 \\
(15.8 \pm 0.83)\end{array}$ & $\begin{array}{c}4.13 \pm 0.66 \\
(7.61 \pm 1.21)\end{array}$ & 0.48 & $1.08 \pm 0.04$ & $0.66 \pm 0.07$ & $-2.03 \pm 0.25$ \\
\hline
\end{tabular}

\footnotetext{
${ }^{\text {a }}$ Site-core-section.

${ }^{b}$ Depth in sediment column.

${ }^{c}$ Numbers in parentheses are for values recalculated on a carbonate-free basis.

$\mathrm{d}_{\text {Activity ratio. }}$

${ }^{e}$ Excess $\mathrm{Th}^{230}=\mathrm{dpm} / \mathrm{gTh}^{230}-\mathrm{dpm} / \mathrm{gU}^{234} ; \mathrm{dpm}=$ disintegration per minute.
}

suggestion of diagenetic uranium enrichment can be more definitely verified if future measurement on samples deeper than 229A-5-6 from the Hole 229A yields $\mathrm{Th}^{230} / \mathrm{U}^{234}$ ratios less than 0.66 .

It is notable that for the three samples with low $\mathrm{Th}^{230} / \mathrm{U}^{234} \quad(228-1-2, \quad 229 \mathrm{~A}-2-1, \quad 229 \mathrm{~A}-5-6)$, their $\mathrm{U}^{234} / \mathrm{U}^{238}$ values are relatively high, implying a significant portion of their uranium as having originated from seawater or pore solution. For $229-1-\mathrm{CC}$, however, both $\mathrm{U}^{234} / \mathrm{U}^{238}$ and $\mathrm{Th}^{230} / \mathrm{U}^{234}$ data point to the possibility that the majority of its high uranium content is of detrital origin.

The present study at best enables us to make an order-of-magnitude estimation of the more recent sedimentation rate at Site 228. It will be assumed from the 228-1-1 data that surface sediments at the site contain about $0.3 \mathrm{dpm} / \mathrm{g}$ (disintegrations per minute per gram) excess $\mathrm{Th}^{230}$. Since precipitation of $\mathrm{Th}^{230}$ produced by decay of $\mathrm{U}^{234}$ in the sea is quantitative, i.e., less than $1 \%$ of the $\mathrm{Th}^{230}$ formed remaining in the sea (Moore and Sackett, 1964), one can estimate that each sqaure centimeter of the Red Sea floor receives about $2.6 \mathrm{dpm}$ of $\mathrm{Th}^{230}$ per thousand years (assuming $1 \mathrm{~km}$ to be the mean depth of the Red Sea and each liter of its water containing about $3.3 \mu \mathrm{g}$ uranium). The concentration of the "authigenic" $\mathrm{Th}^{230}$, or $\mathrm{Th}_{e x}^{230}$, in a newly deposited sediment will then be approximately $2.6 / \rho \times R(\mathrm{dpm} / \mathrm{g})$ where $R$ is the sedimentation rate in $\mathrm{cm} / 10^{3} \mathrm{yr}$, and $\rho$ the water-free, uncompressed bulk density of the surface sediments in $\mathrm{g} / \mathrm{cm}^{3}$. By taking $\rho$ to be $0.9 \mathrm{~g} / \mathrm{cm}^{3}$ (cf. Report on Physical Properties and Water Contents, Site 228$), \mathrm{Th}_{e x}^{230}$ to be 0.3 $\mathrm{dpm} / \mathrm{g}, R$ should be of the order of $10 \mathrm{~cm} /{ }^{3} \mathrm{yr}$. This corroborates with the radiometric results obtained previously on lutite cores retrieved from that part of the Red Sea $(\mathrm{Ku}$ et al., 1969; Ku, 1969).

\section{ACKNOWLEDGMENTS}

I thank Steven Murray and Henry Ko for help in the laboratory. This work was supported in part by the Oceanography Section, National Science Foundation, NSF Grant GA-35407.

\section{REFERENCES}

Goldberg, E. D., 1965. Minor elements in sea water. In Chemical oceanography: Riley, J. P. and Skirrow, G., (eds.), New York (Academic Press), v. 1, p. 163-196.

Kolpack, R. L. and Bell, S. A., 1968. Gasometric determination of carbon in sediments by hydroxide absorption: J. Sediment. Petrol., v. 38, p. 617.

$\mathrm{Ku}, \mathrm{T}$. L., 1965. An evaluation of the $\mathrm{U}^{234} / \mathrm{U}^{238}$ method as a tool for dating pelagic sediments: J. Geophys. Res., v. 70, p. 3457 .

1969. Uranium series isotopes in sediments from the Red Sea hot-brine area. In Hot brines and recent heavy metal deposits in the Red Sea, Degens, E. T. and Ross, D. A., (eds.), New York (Springer-Verlag), p. 512-524

Ku, T. L., Thurber, D. L., and Mathieu, G. G., 1969. Radio-carbon chronology of Red Sea sediments. In Hot brines and recent heavy metal deposits in the Red Sea: Degens, E. T. and Ross, D. A., (eds.), New York (Springer-Verlag), p. 348-359.

Moore, W. S. and Sackett, W. M., 1964. Uranium and thorium series inequilibrium in sea water. J. Geophys. Res., v. 69 , p. 5401 . 